\title{
WSRC REACTOR TANK INSPECTION PROGRAM (RTIP) STATUS REPORT
}

\author{
PREPARED BY \\ MARC W. LOIBL \\ WESTINGHOUSE SAVANNAH RIVER COMPANY \\ SAVANNAH RIVER LABORATORY \\ AIKEN, SOUTH CAROLINA, 29808
}

A PRESENTATION FOR THE

\section{RD WEAPONS AGENCIES NONDESTRUCTIVE TESTING ORGANIZATION MEETING}

\author{
LIVERMORE, CALIFORNIA \\ MARCH 10-12, 1992
}

This presentation was prepared in connection with work done under Contract No. DEAC09-89SR18035 with the U.S. Department of Energy. By acceptance of this publication, the publisher and/or recipient acknowledges the U.S. Government's right to retain a nonexclusive, royalty-free license in and to any copyright covering this presentation, along with the right to reproduce and to authorize others to reproduce all or part or the copyrighted presention.

\section{MYSTSER}


WSRC-MS-92-105

\section{Introduction:}

Westinghouse Savannah River Company (WSRC) recently completed the inital phase of nondestructive inspections of the Savannah River Site's (SRS) reactor tanks. This program required almost three years to be conceptualized, designed, fabricated, and tested. An additional 20 months were required to complete the NDE inspection of the $\mathrm{P}, \mathrm{K}$ and $\mathrm{L}$ reactor tanks. The overall cost of the program to date is approximately $\$ 25 \mathrm{MM}$. This status report will address:

1) A brief review of the RTIP program and the constraints which had to be overcome.

2) A summary of the examination results of the P, K, and L Reactor tanks.

3) A projection of the future enhancements and capabilities presently in development.

\section{Program Review:}

The SRS reactor tanks were fabricated and installed in the mid-fifties. The tanks are approximately 16 feet in diameter and 25 feet in overall height. The main tank is approximately 15 feet in height and consists of two stainless steel rings with two sheets in each ring (the $L$ tank consists of three sheets in earh ring). There is no external access to any of the reactor tanks due to the concrete biological shield. Although the upper plenum of the reactor tanks was originally designed to be removed to allow interal access, subsequent to installation, the plenums were permanently attached to the main tank. Therefore, the only access to the interior of the reactor tanks is through one of the $6804.375 "$ I.D. Universal Sleeve Housings (USH) w'nich are part of the upper plenum.

When the tanks were fabricated by New Yark Shipbuilders, the welds and, subsequently, the completed tanks were extensively inspected oy $100 \%$ radiography, liquid penetrant, and leak detection. In turn, during the field installation, the closing seams of the tanks were also inspected in the same way and all inspections were evaluated in accordance with the 1948 ASME Code acceptance criteria. After start-up of the reactors, a documented program was established which provided for regular visual inspections of the reactors on a periodic basis during the $38+$ years that the tanks have been in operation. The results of the inspections were catalogued and compared to previous inspections in order to detect service induced degradation.

Due to tine deposition of an altiminum oxide on the reactor tank walls from the normal operation of the reactors, the visual examinations became progressively less effective. Therefore, In 1986, the inspection program was expanded to include an internal hydro-blast to remove the oxide followed by a water-washable liquid penetrant examination of the $\mathrm{L}$ reactor tank using remote tooling to allow access to the reactor tank welds. Periscope cameras and video equipment were 
used to record the results of this examination.

Due to the remote nature of the examination, a concise resolution of several indications was not possible. These results identified the need for a volumetric examination which could be remotely conducted, preferably underwater, and would yield a concise evaluation of the tanks' integrity. This program was conceptualized in early 1987 and won approval/funding later that year.

A materials structural analysis determined that the primary mode of failure of the tanks would be due to InterGranualar Stress Corrosion Cracking (IGSCC) in the Heat Affected Zones (HAZ's) of the tanks. The concept for a robotically delivered NDE system included:

Visual Capability - In-tank cameras to monitor the equipment operation and to provide a visual record of areas which may contain flaws.

Ultrasonic (UT) Capability - The primary interrogation method for detecting IGSCC.

Eddy Current Capability - A secondary interrogation method to be used to confirm UT results and to be used to accurately locate welded seams in the tank shell under the oxide layer.

Computer Controlled - The delivery system and data acquisition systems would act as "slaves" to the host computer in order to archive the inspection results on a computerized data base.

The inspection system consisted of the following components:

1) Mobile Control Trailer (MCT): This 40 foot van houses the video/audio controls; the system cisiaters; the NDE acquisition systems; and storage compartments.

2) Cabling Penetration: This allows the "clean" exterior cabling to be coupled to the cabling inside the process room without compromising the integrity of the reactor building.

3) In-tank Robot: The robot is controlled by the host Motorola ${ }^{\mathrm{TM}}$ located in the MCT and delivers the UT transducer and the ET probe to the tank wall.

4) In-tank Cameras: Three in-tank, radiation hardened, Rees ${ }^{\mathrm{TM}}$ cameras.

5) In-tank Calibration Mast: The mast holds calibration blocks which allowed in-tank system checks/calibrations to assure adequate system sensitivity.

6) Tank-top Cameras: The tank top cameras allowed visual monitoring of the tool handling personnel during insertion and removal operations. 
7) Erector and Strongbacks: The strongbacks provided protection to the tools during transportation/handling. The erector provided a way to safely bring the in-tank tools to vertical prior to inserting them into the tank.

8) 2-Ton Overhead Crane: A program-specific bridge crane to provide highly accurate tool positioning capabilities.

9) Full-Scale Mock-Up: Reactor mock-up tank used for technique development, personnel training, and programmatic qualifications.

In parallel with the hardware development, the UT and ET techniques were also defined, procedurealized, and tested. In order to qualify the equipment, techniques, and personnel, a performance-based program was established using cracked plates in conjuction with the site specifice program. The qualification was defined and administered by the Electric Power Research Institute (EPRI) Center for NDE. All inspection personnel were required to successfully complete the qualification program prior to participation in the actual inspection.

\section{Results:}

All development and qualification activities were completed in August, 1989. The first field deployment of the program to the P reactor was started in September, 1989. The P inspection required approximately two months to complete approximately $40 \%$ of the accessible HAZ's in the reactor tank. Due to the success of the P inspection, our customer directed WSRC to continue with the program and inspect the $\mathrm{K}$ reactor tank starting 60 days after completion of the P exam.

The $\mathrm{K}$ inspection was started in January, 1990. The scope of this inspection was to examine a minimum of $40 \%$ of the tank's accessible HAZ's or to continue the examination until mid-march, whichever came first. Although the equipment start-up phase of the inspection required in excess of a week, the performance of the equipment quickly made up for the slow start. Design changes implemented during the equipment refurbishment allowed the $\mathrm{K}$ inspection to examine approximately $60 \%$ of the K tank's accessible HAZ's before the 3/15/90 deadline. This prompted our customer to extend a formal Commendation to the Savannah River Lab as an expression of their appreciation for a quality job.

The final inspection was performed in the $\mathrm{L}$ reactor tank from October, 1990, through April, 1991. The equipment start-up phase of the inspection was slightly shorter than that of the K exam. The equipment performance was, again, very reliable. Although several delays were encountered during the inspection which were associated with other site activities, $100 \%$ of the $\mathrm{L}$ tank's accessible HAZ's were examined for the presence of IGSCC.

The RTIP program remotely examined almost 600 feet of weld during the 20 months of the inspection. All UT inspection data bas been stored on optical discs for future use. Also, the ET data has been stored on bernoulli discs for future reference. The quality of the video footage 
obtained from the inspections far exceeds any previous visual media.

The results of the inspections were presented to the Defense Nuclear Facilities Safety Board (DNFSB) in May, 1991, and received their endorsement. This met a major milestorie in the reactor restart process.

\section{Path Forward:}

The geometry of the in-tank robot does not currently allow inspection of the shell-to-bottom "TWeld". Neither can it address the bottom six inches of the vertical nozzle insert welds ("VF" welds).

In order to examine these welds, an ultrasonic immersion technique is being developed which will require a revised end effector be designed for the robot. In the place of the present contact end effector, a six-degree-of-freedom, non-contact manipulator will position the UT immersion transducer a constant 14 inches fro the tank wall. Positional feedback will monitor the location and angulation of the UT trans/ucer in order to track and maintain the proper signal entry angle. Positioning accuracy of the end effector will be within 0.5 degrees.

Technique development of this capability is underway and is currently scheduled for implementation in FY94 or early FY95. Pending successful qualification of this method, the contact method currently being used for the RTIP work will be discontinued and the immersion technique will replace it.

Also being under development is a pipecrawler which will deliver UT/ET/VT capability to embedded welds in the reactor process water piping. The crawler is a modified version of a commercially available product. The modifications allow the crawler to automatically adapt from a 12" diameter pipe to diameters up to 16". The crawler will be interfaced with a host computer along with the data acquisition system to enable fully automated scanning and data storage. The NDE data acquisition and analysis systems will be the same as the systems in use for the tank inspection work. Our present implementation date for the pipecrawler is early FY93.

This presentation was prepared in connection with work done under Contract No. DEACO4-89SR 18035 with the U.S. Department of Energy. By acceptance of this publication, the publisher and/or recipient acknowledges the U.S. Government's right to retain a nonexclusive, royalty-free license in and to any copyright covering this presentation, along with the right to reproduce and to authorize others to reproduce all or part of the copyrighted presentation. 


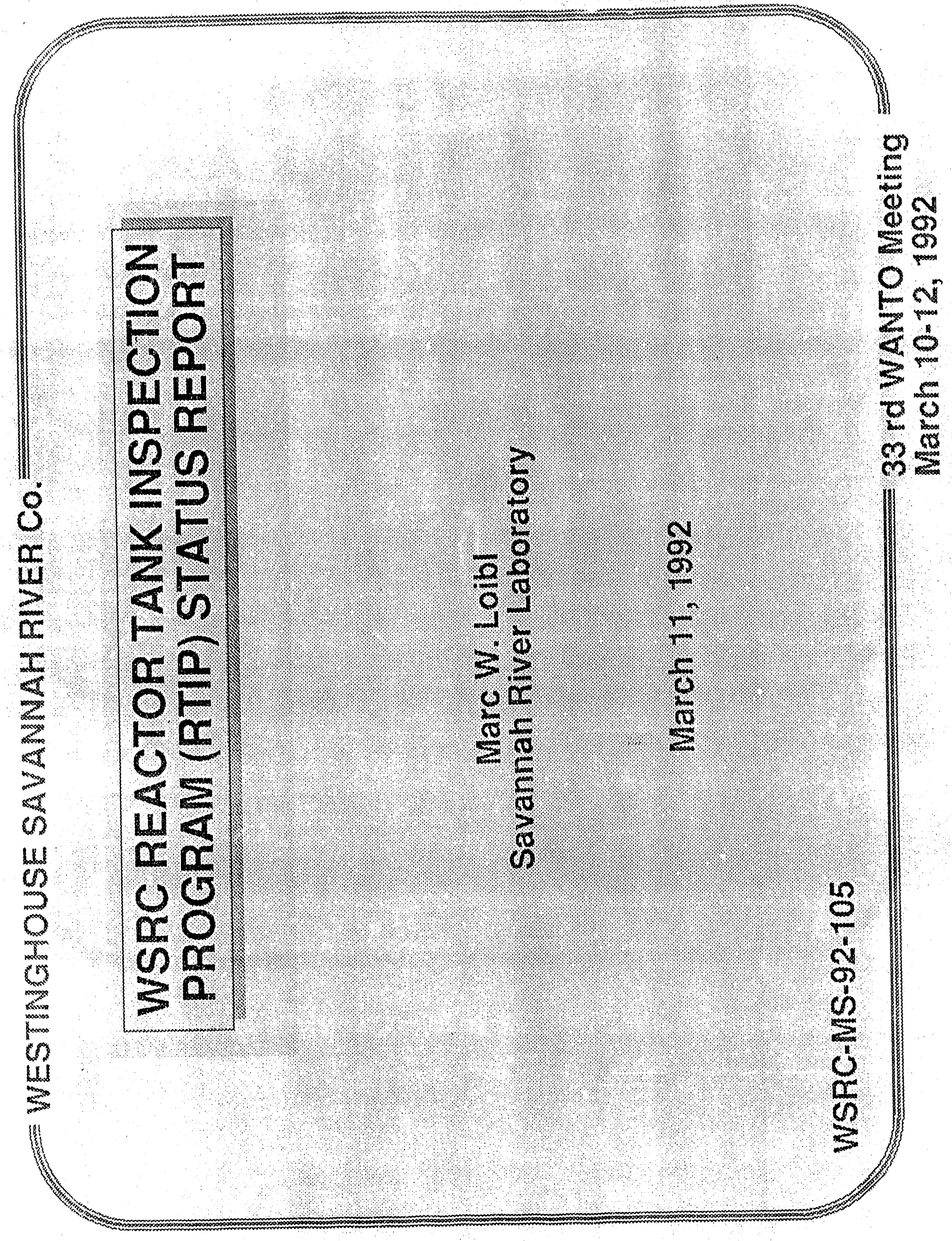




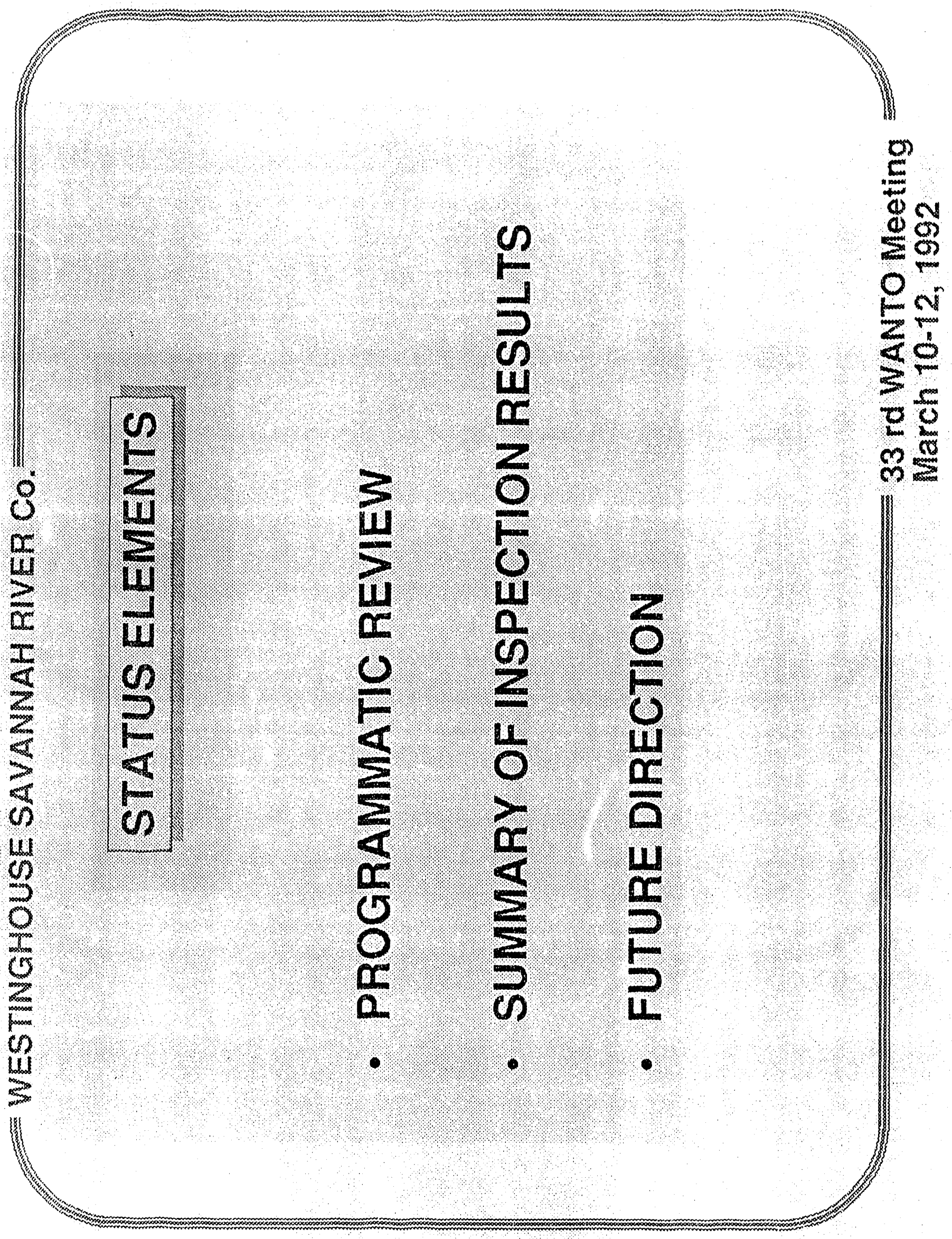




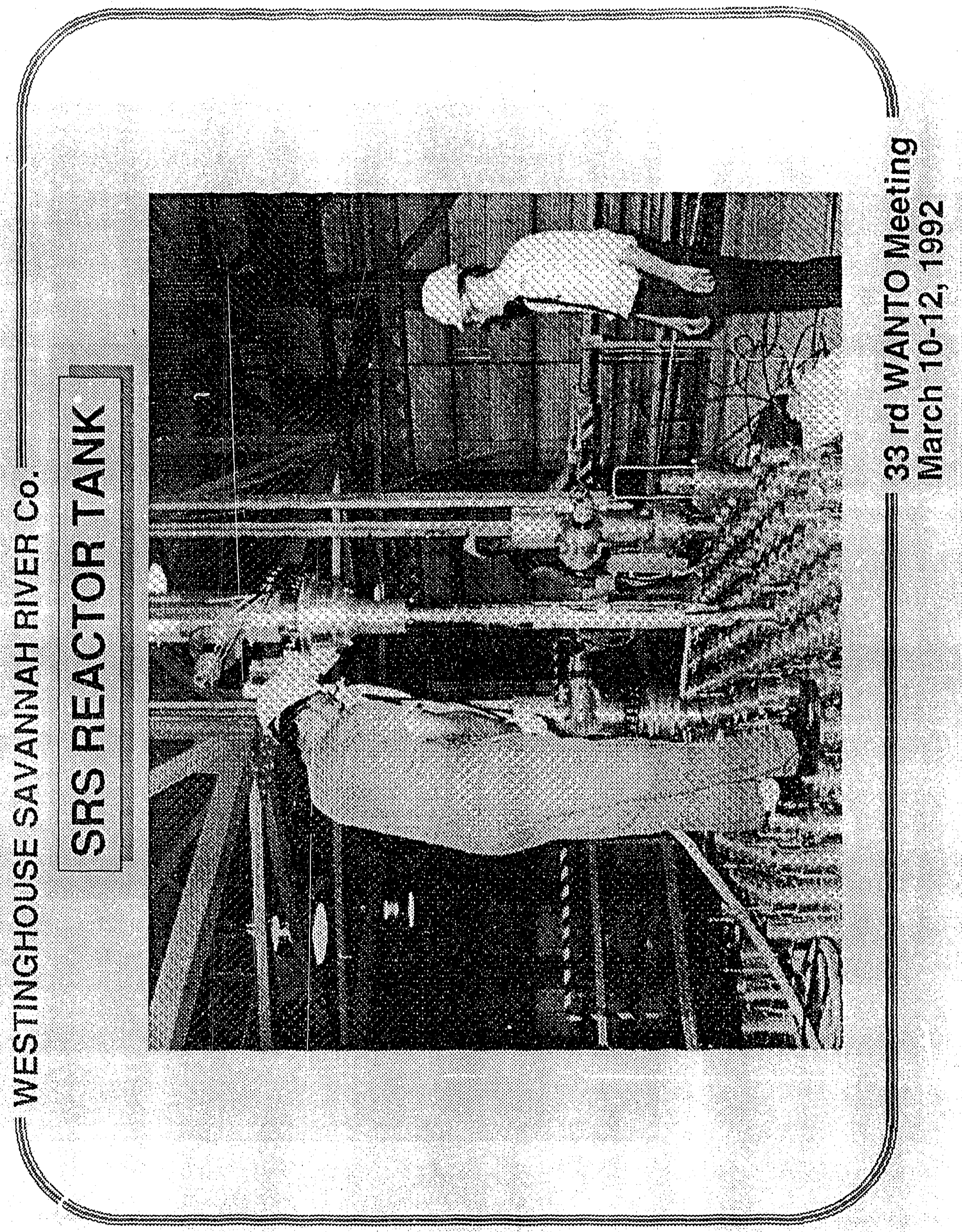




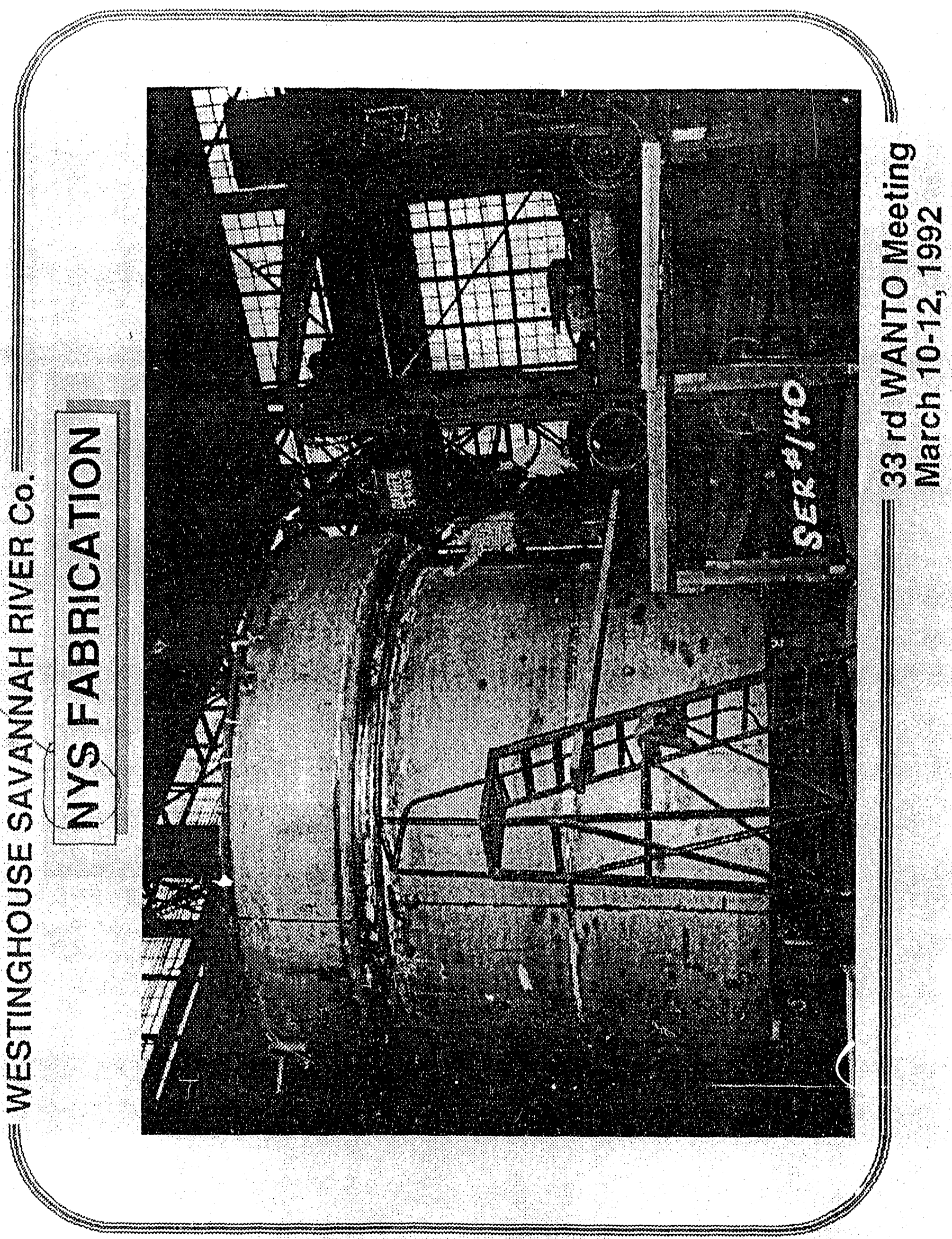




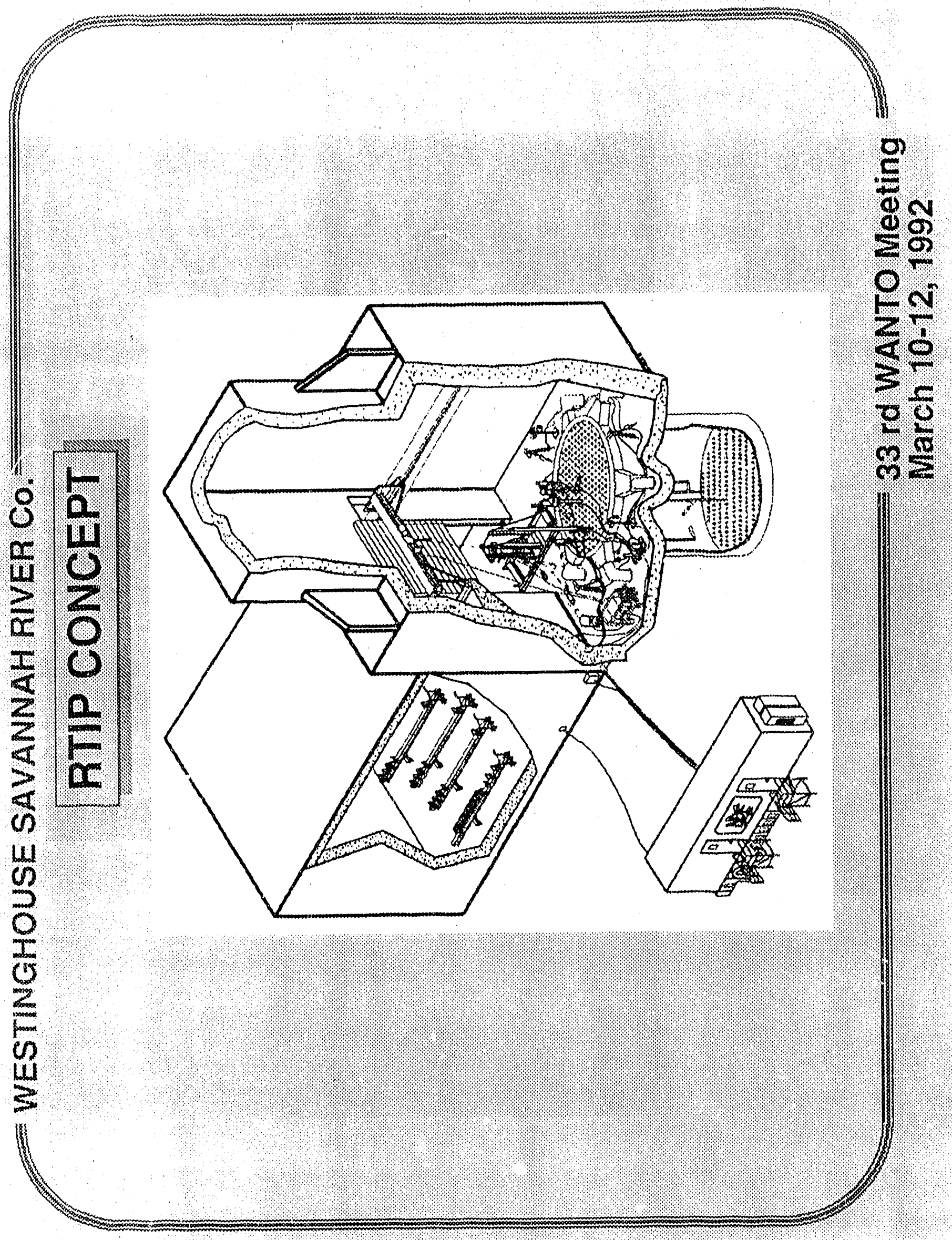




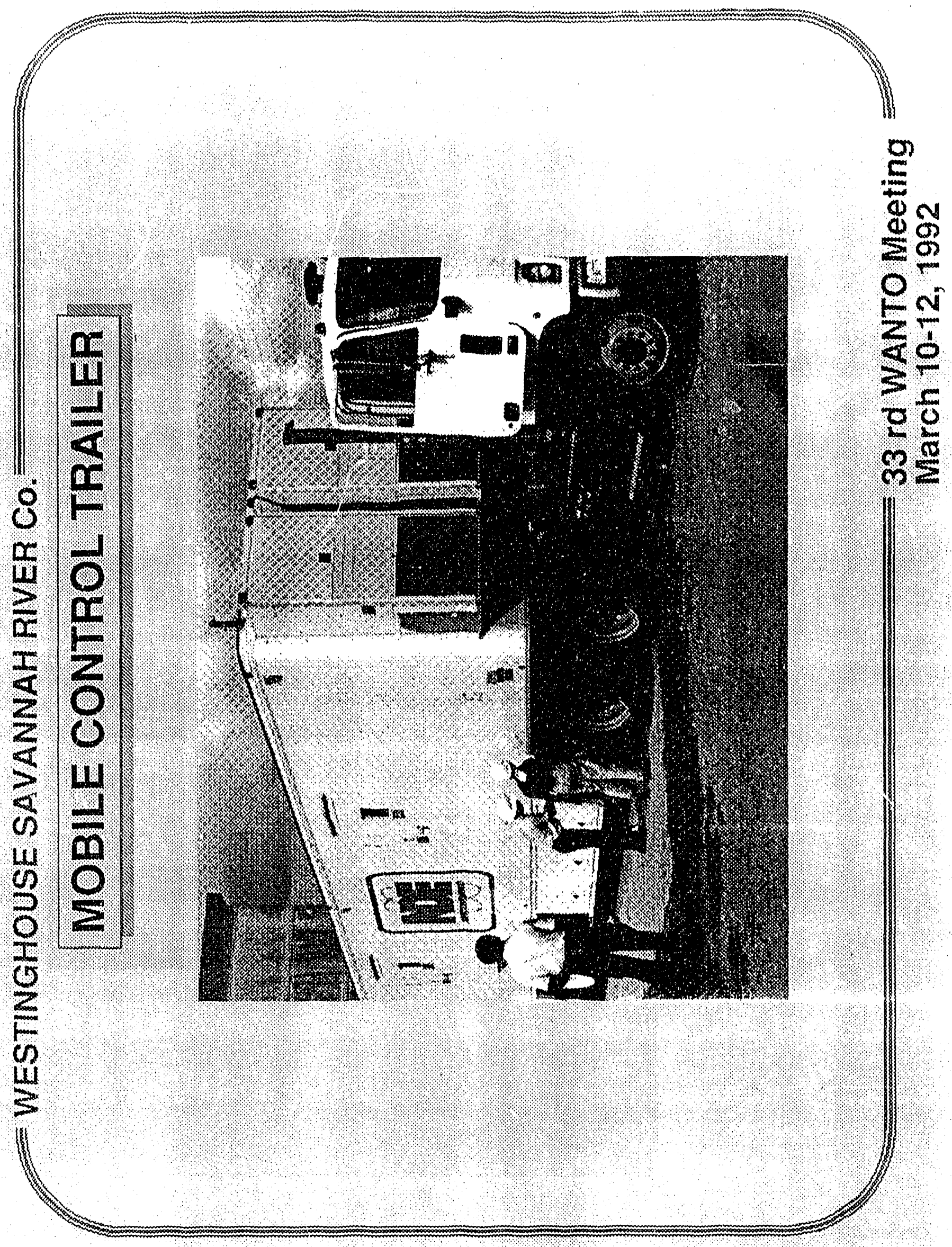




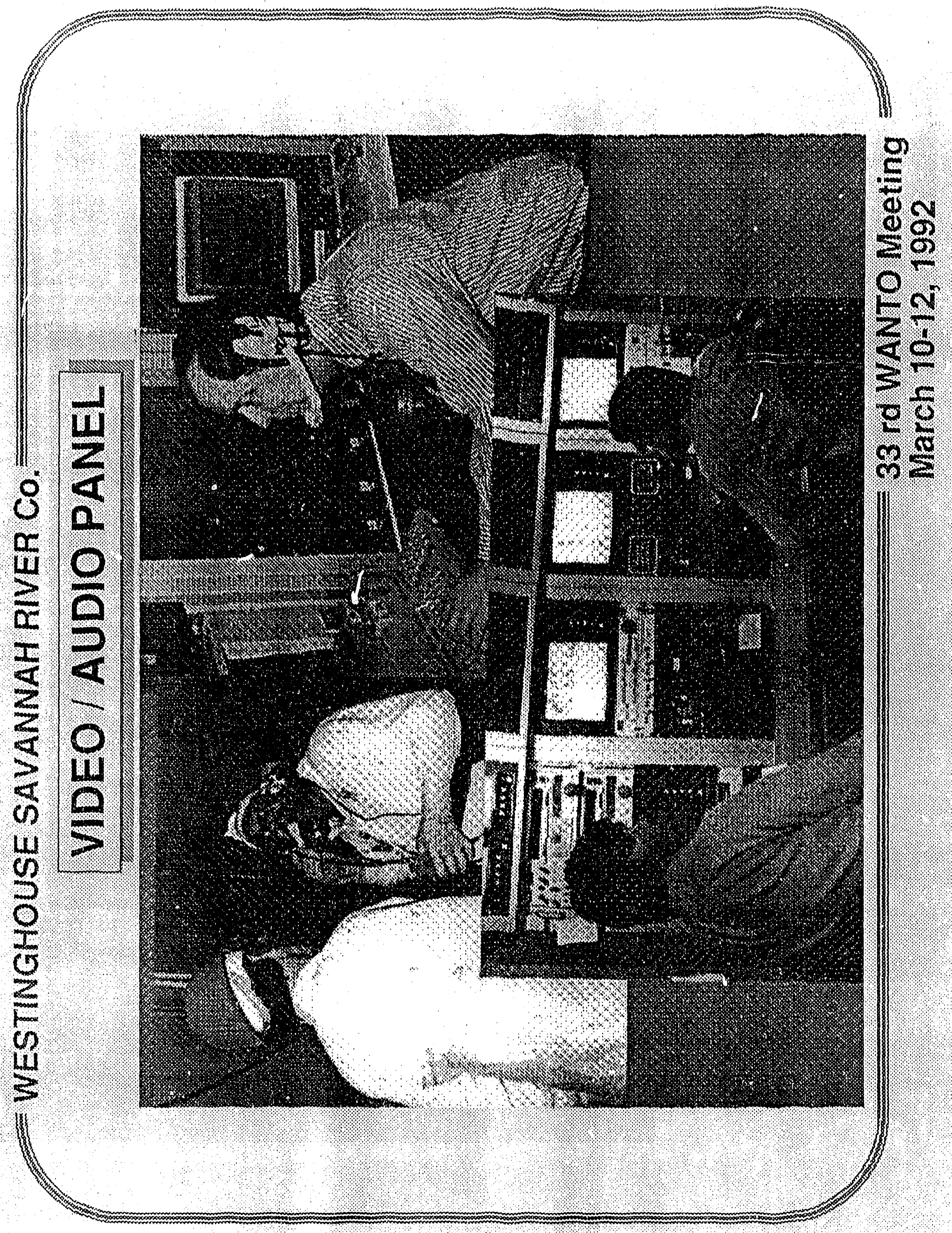




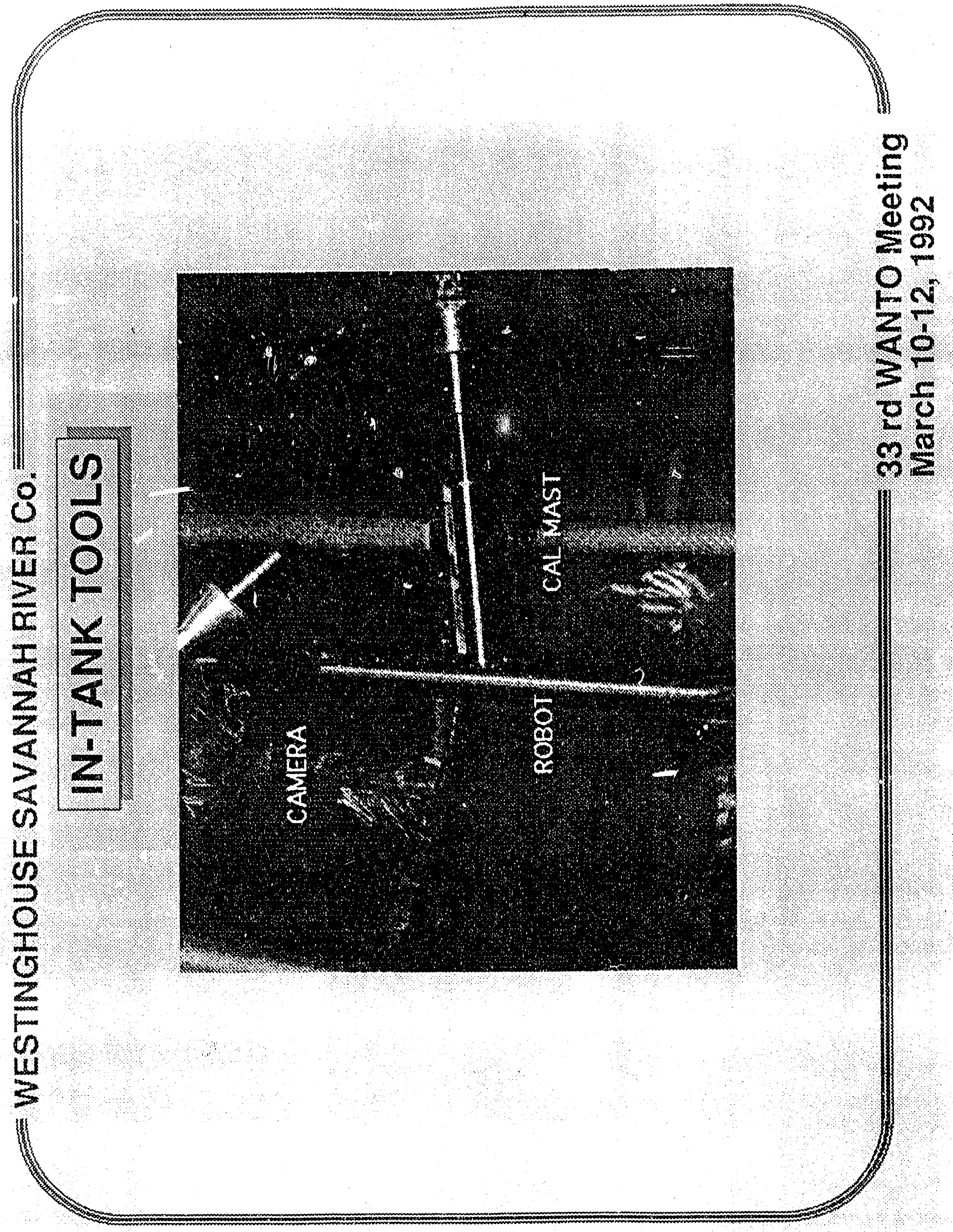




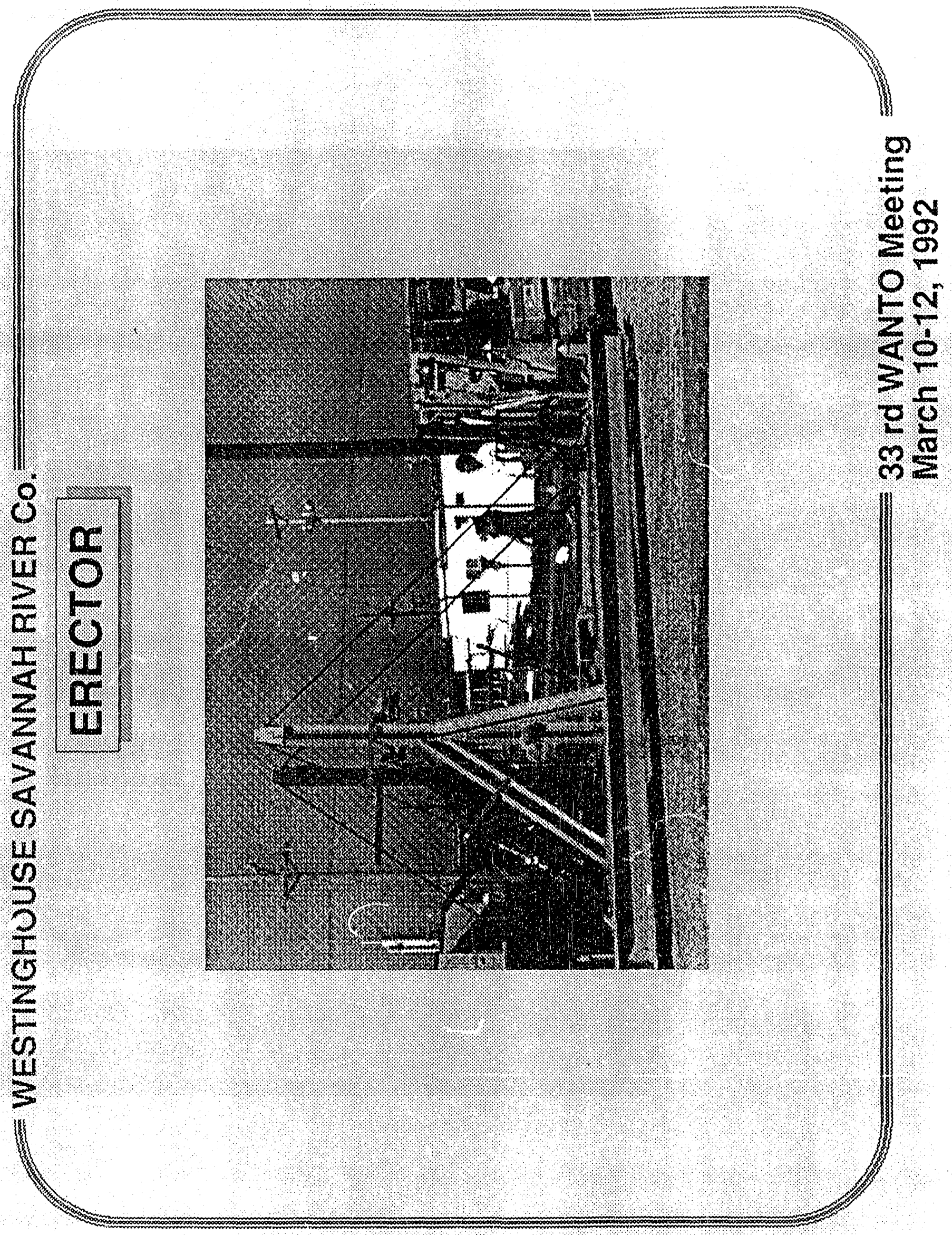




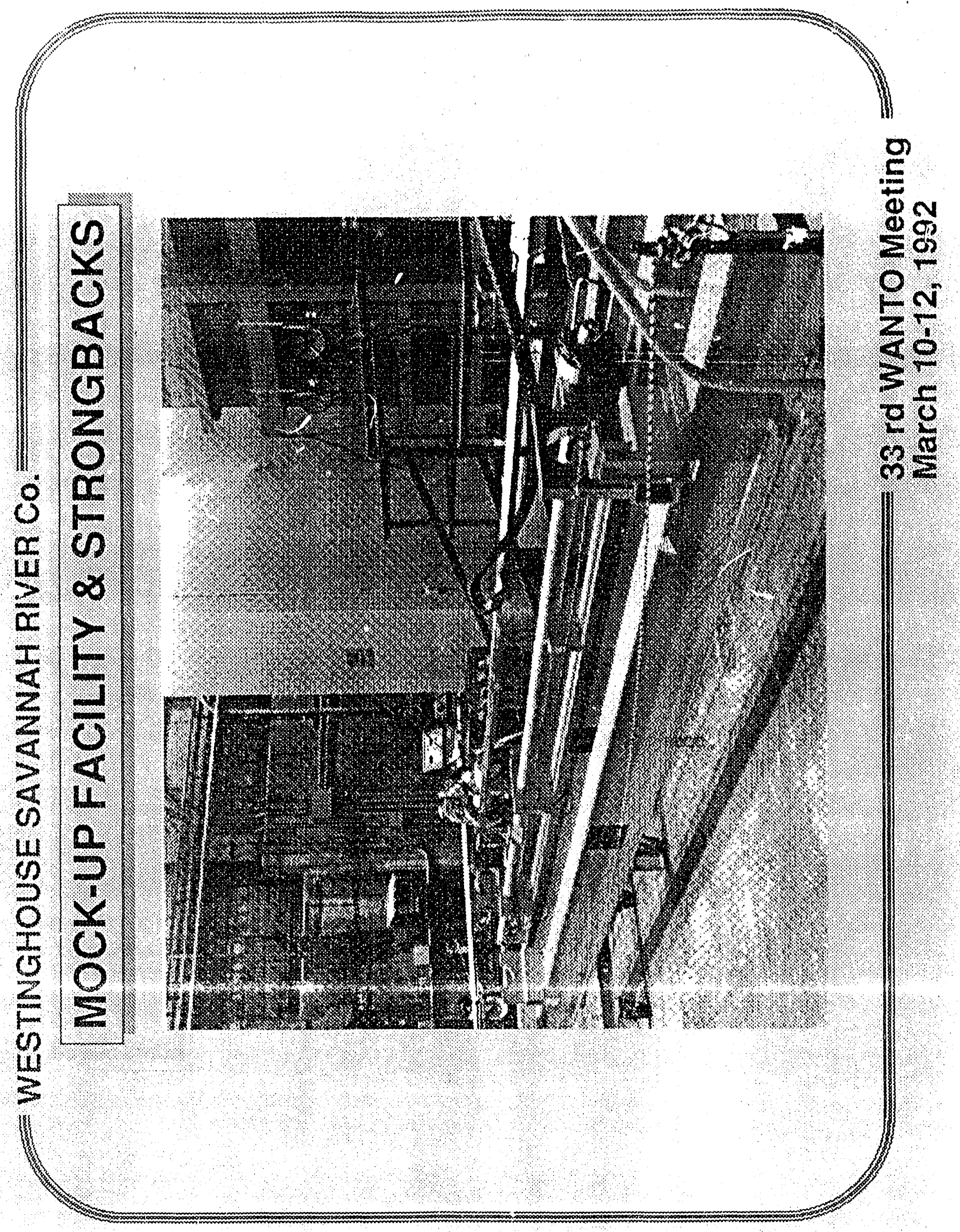




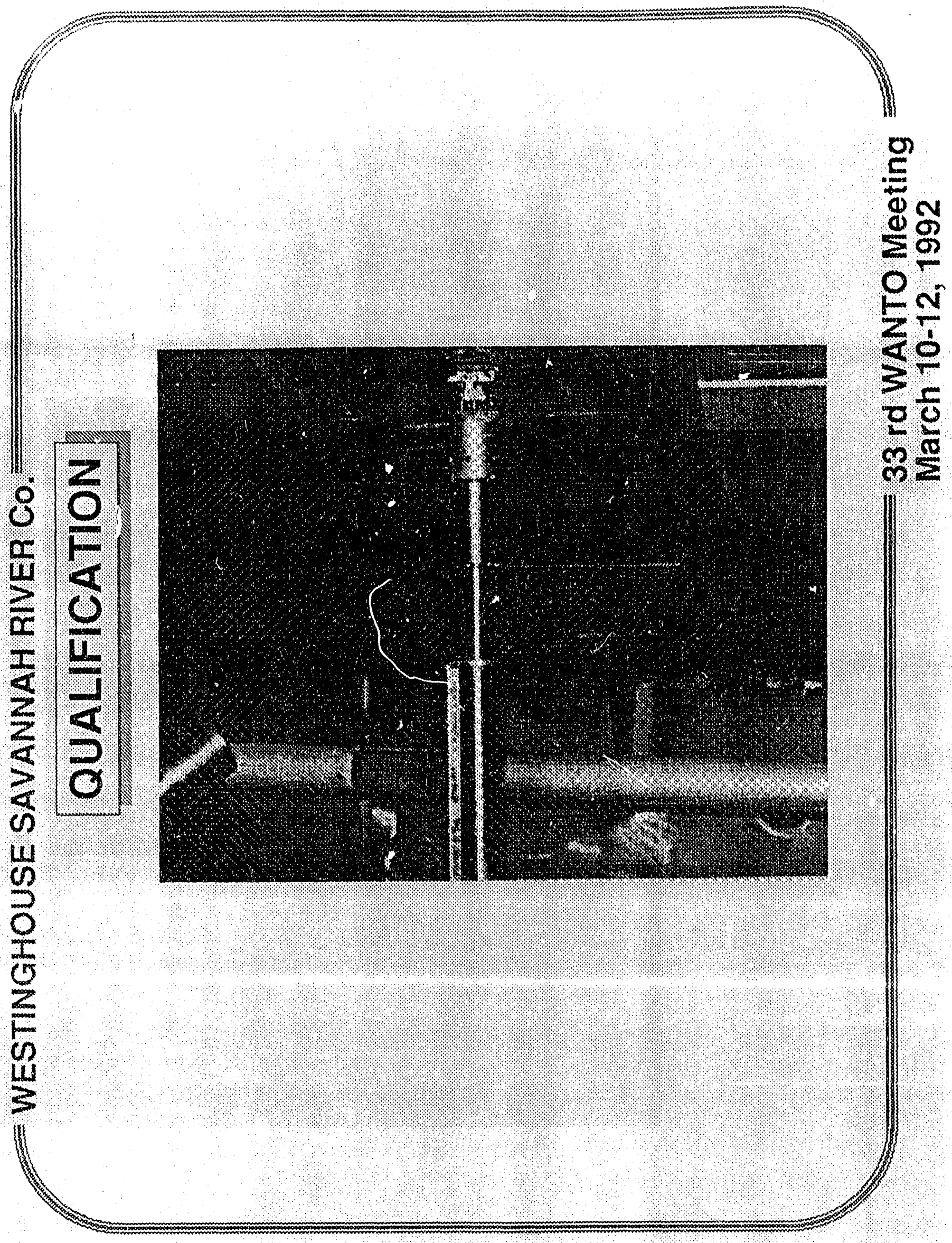




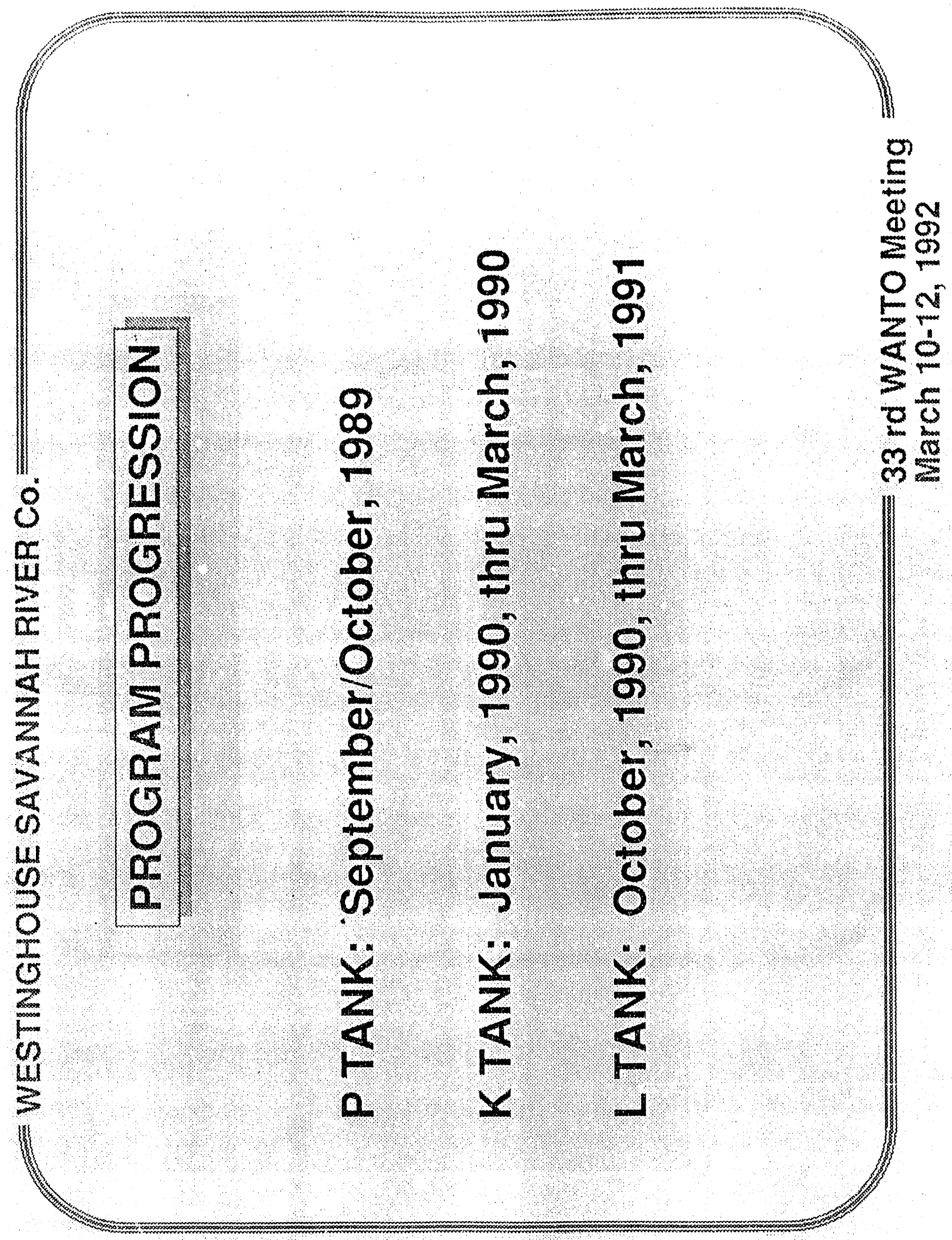




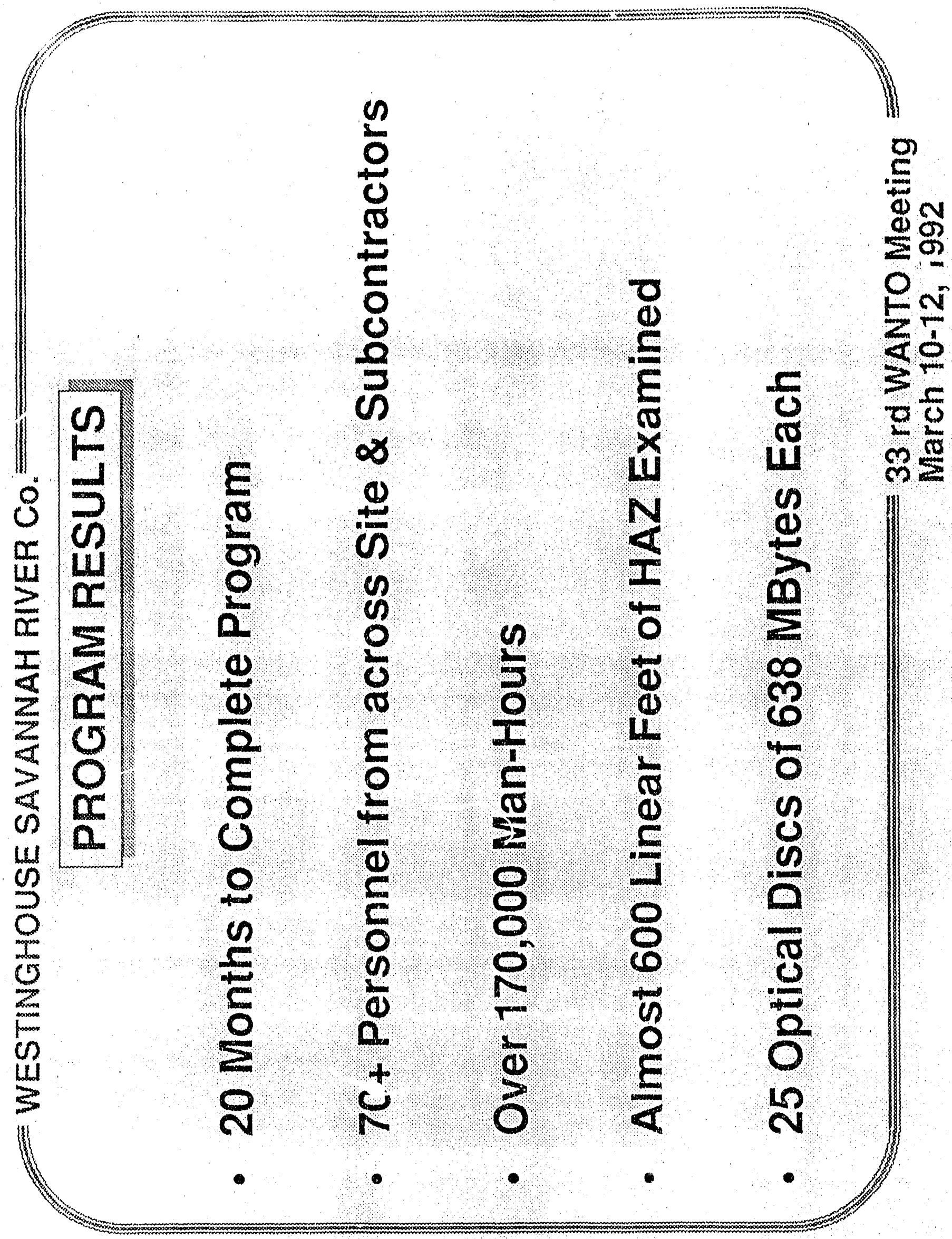




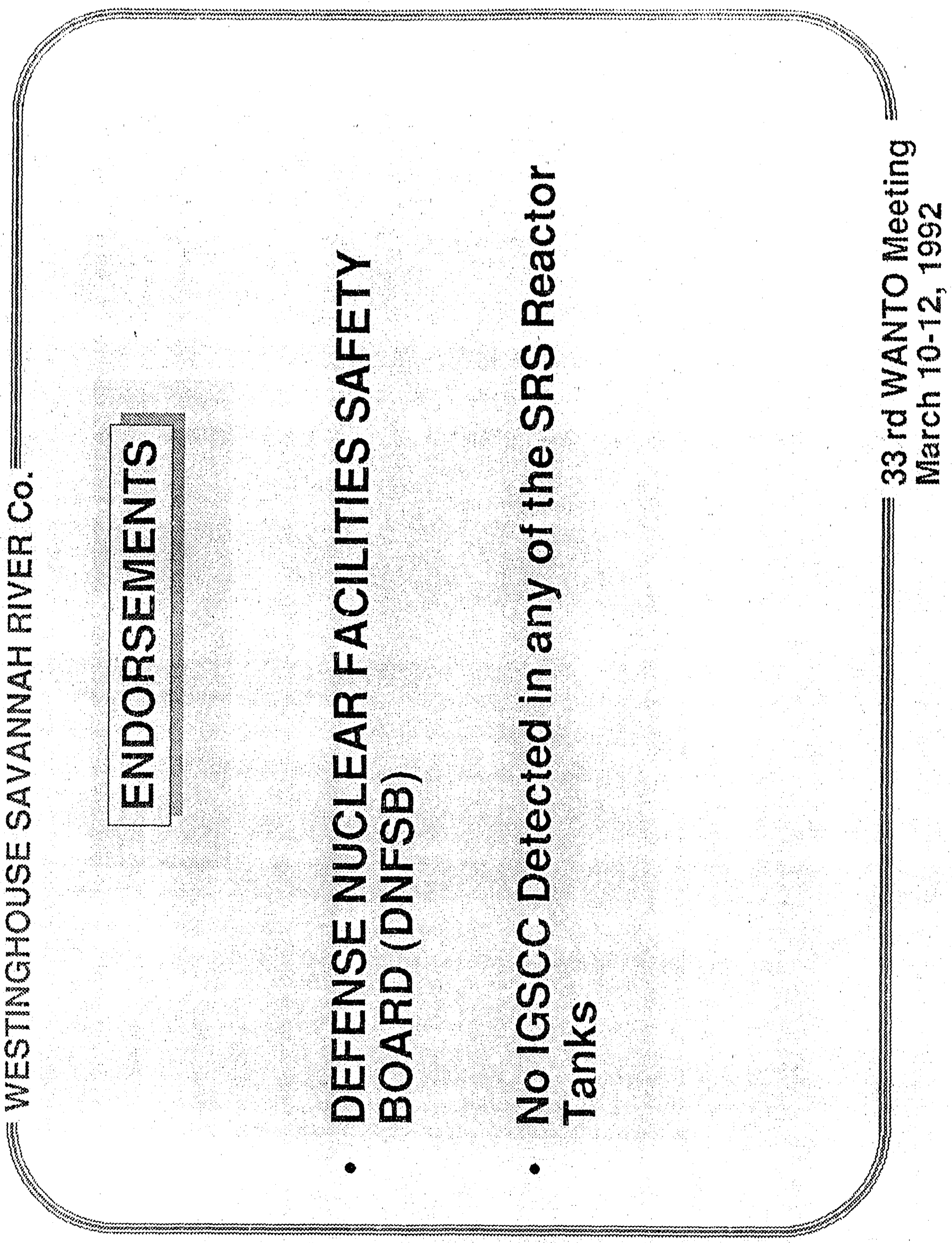




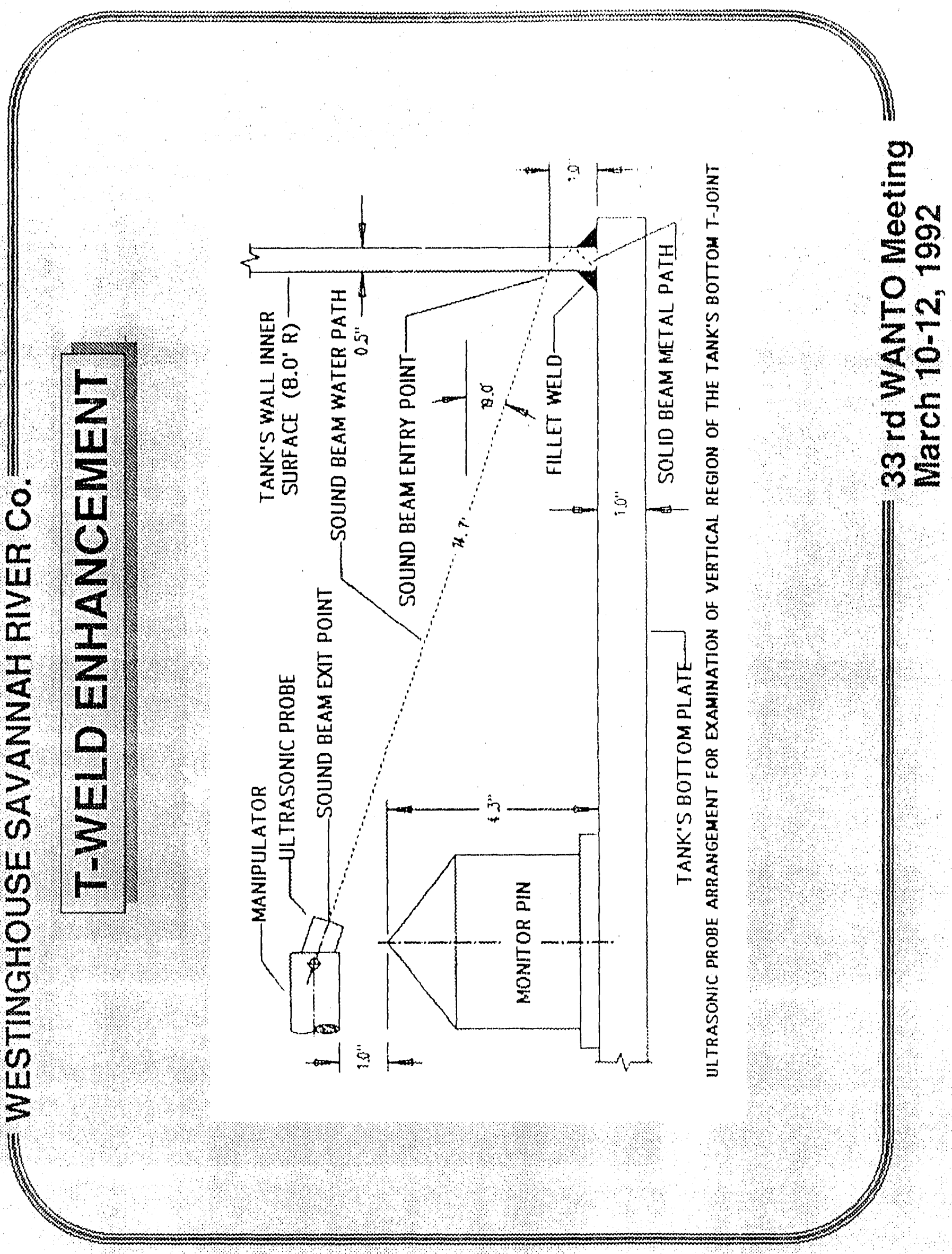




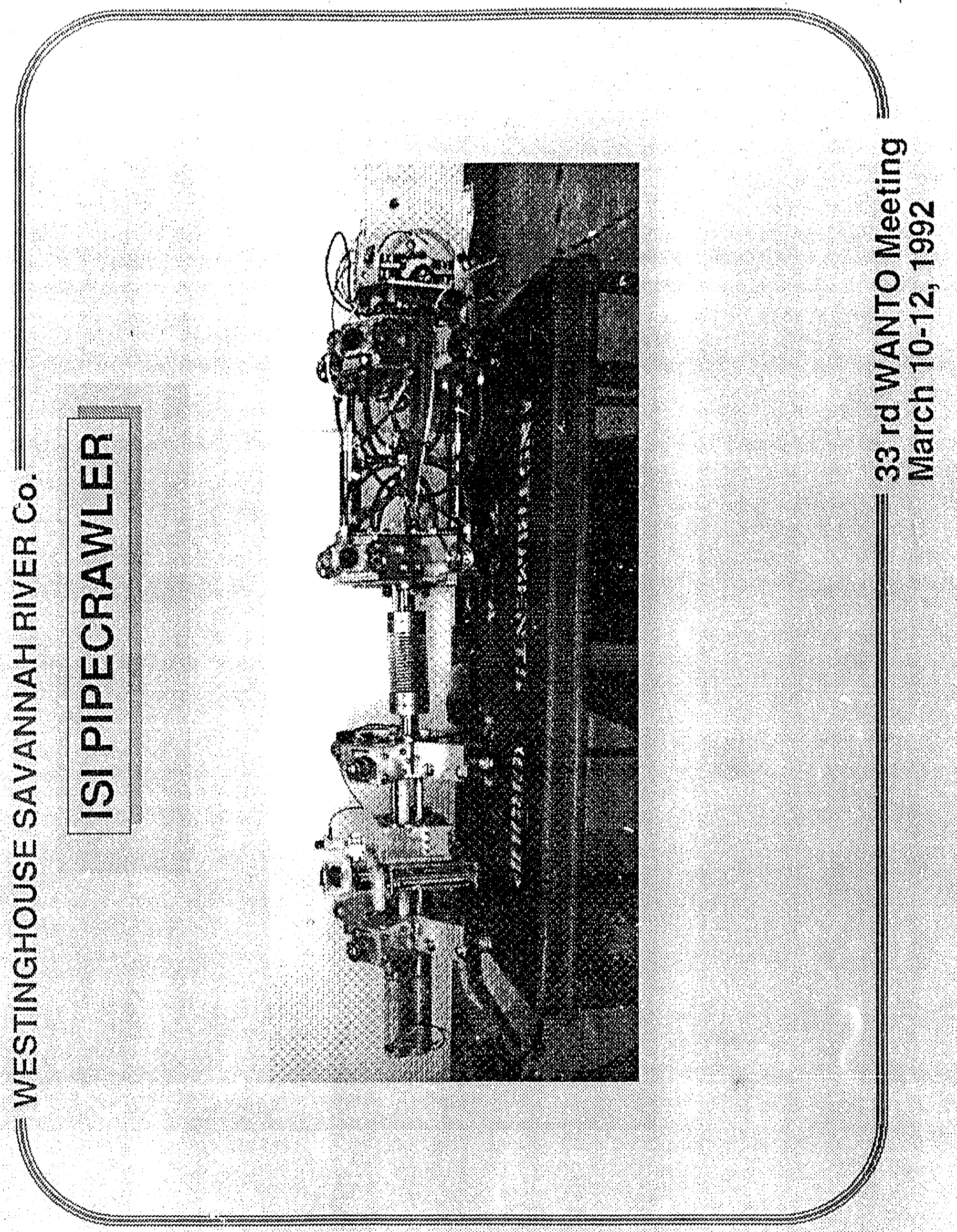



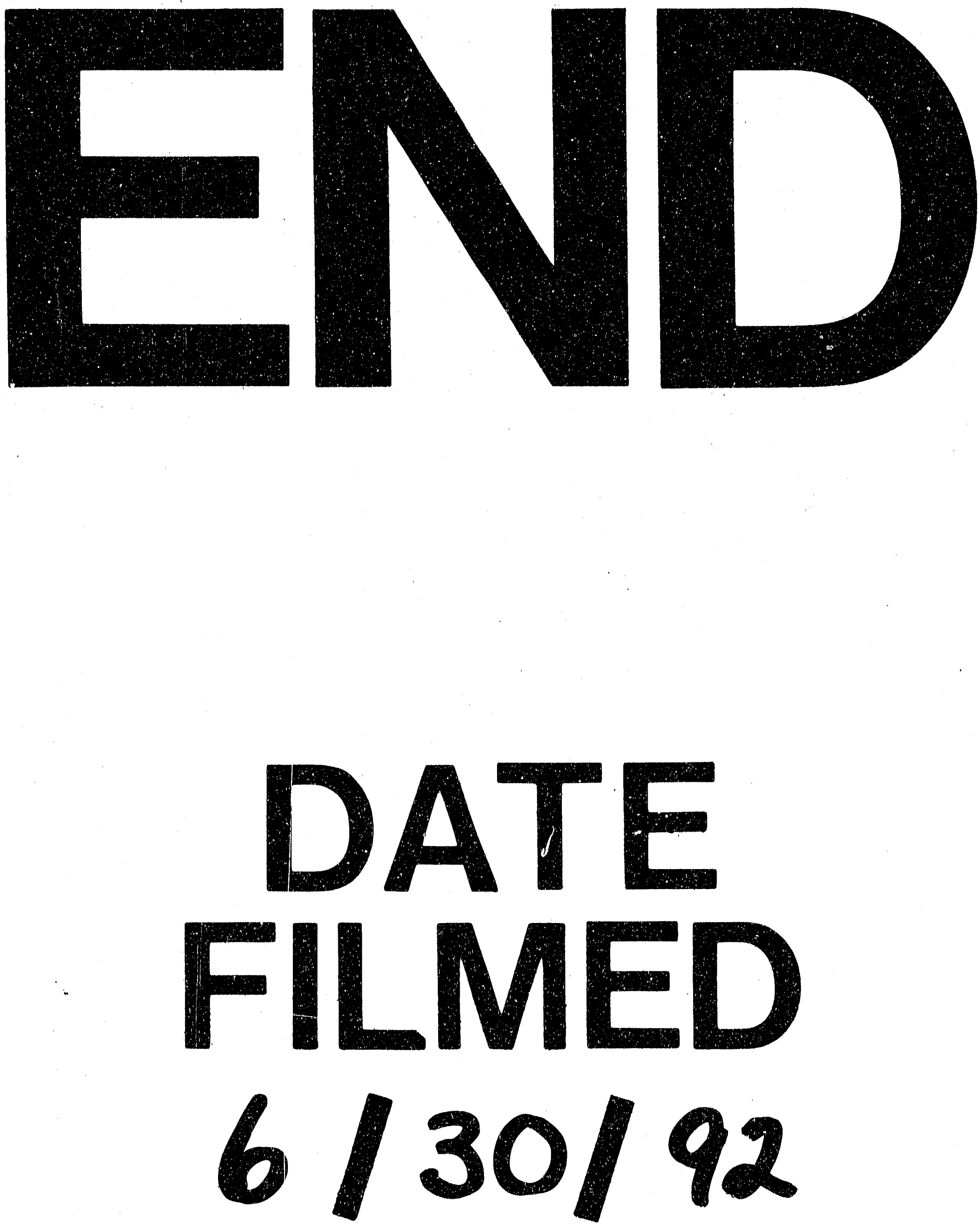
